\title{
ILMU PENGETAHUAN DAN TEKNOLOGI DALAM SUDUT PANDANG ISLAM
}

\author{
Ariyadi \\ Dosen Tetap Yasan Muhammadiyah Palangkaraya Fakultas Agama Islam \\ Jl.RTA Milono Km. 1,5 Telp/Fax (0536) 3237104 Palangka Raya 73111 \\ E-mail : ariyadialbanjari@gmail.com
}

\begin{abstract}
ABSTRAK
Era modern saat kita sebagai kaum muslim di hadapkan pada arus tantangan globalisasi yang semakin komliks untuk itu memanfaatkan teknologi di jalan yang baik agar bisa bermanfaat untuk umat, bangsa dan agama. Sudah seyugyanya umat Islam tidak hanya memanfaatkan teknologi saja, saatnya berkreasi untuk menciptakan teknologi baru. Dan kita tunjukkan bahwa kaum Muslim juga mampu membuat dan mapu bersaing di bidang teknologiteknologi yang handal, kreatif dan inovatif.

Tafsir yang ada pada kitab Al-Qurthubi, ayat ini merupakan pokok landasan tentang upaya pembuatan alatalat dan sebab-sebab. Allah Ta'ala telah mengabarkan tentang Nabi Daud AS, bahwa ia membuat baju besi, teropong, dan makan dari hasil kerjanya sendiri. Sementara Adam adalah seorang petani, Nuh seorang tukang kayu, Luqman seorang penjahit, dan Thalut adalah penyamak kulit. Tafsir di atas Islam menganjurkan untuk menciptakan atau menggunakan alat yang dapat memudahkan pekerjaan kita. Itulah teknologi, dan ternyata ide pemanfaatan teknologi ini ada di dalam Al-Qur'an. Teknologi itu memang memiliki dua sisi. Dia bisa bermanfaat jika digunakan dengan tujuan yang baik, atau bisa menjadi musuh jika digunakan untuk tujuan yang tidak baik.
\end{abstract}

Kata Kunci : Globalisasi, Teknologi, Tafsir

\section{ABSTRACT}

The modern era when we as Muslims in hadapkan on the current challenges of globalization are increasingly komliks to it make use of technology in a good way for it to be beneficial to the people, nation and religion. Already seyngyanya the Muslims not only make use of technology, time coding to create new technology. And we show that the Muslims are also able to create and compete at mapu technology-technology that is reliable, creative and innovative.

Tafsir on Al-Qurthubi, this verse is a staple of the Foundation about the attempt of making tools and reasons. Allah Ta'ala has preached about the Prophet David, that he makes US armor, binoculars, and eat of his work itself. While Adam is a farmer, Nuh a Carpenter, a tailor, Luqman and So is the tanners. The above interpretation of Islam advocated to create or use a tool that can facilitate our work. That's the technology, and it turns out that the idea of utilization of this technology is in the Qur'an. Technology it does have two sides. He could be beneficial if it is used with the aim of a good, or it could be the enemy if it is used for purposes that are not good.

Kata Kunci : Globalisasi, Teknologi, Tafsir

\section{Pendahuluan}

Manusia adalah makhluk yang unik. Manusia memiliki akal budi, rasa, karsa, dan daya cipta yang digunakan untuk memahami eksistensinya, dari mana sesungguhnya ia berasal, dimana berada dan akan kemana perginya. Pertanyaanpertanyaan selalu muncul, akan tetapi pertanyaan itu belum pernah berhasil dijawab secara tuntas. Manusia tetap saja diliputi ketidaktahuan. Demikianlah sesungguhnya manusia, siapa saja, eksis dalam suasana yang diliputi dengan pertanyaan-pertanyaan.Manusia eksis di dalam dan pada dunia filsafat dan filsafat hidup subur di dalam aktualisasi manusia. 
manusia miliki rasa, karsa dan daya cipta yang mengembangkan ilmu pengetahuan dan teknologi. Namun, perkembangan teknologi yang luar biasa menyebabkan manusia "lupa diri. Manusia menjadi individual, egoistik dan eksploitatif, baik terhadap diri sendiri, sesamanya, masyarakatnya, alam lingkungannya, bahkan terhadap Tuhan Sang Penciptanya sendiri.Karena itulah filsafat ilmu pengetahuan dihadirkan ditengah-tengah keaneka ragaman IPTEK untuk meluruskan jalan dan menepatkanfungsinya bagi hidup dan kehidupan manusia di dunia ini.

Kemajuan sains dan teknologi telah memberikan kemudahan-kemudahan dan kesejahteraan bagi kehidupan manusia sekaligus merupakan sarana bagi kesempurnaan manusia sebagai hamba Allah dan khalifah-Nya. Allah telah mengaruniakan anugerah kenikmatan kepada manusia yang bersifat saling melengkapi yaitu anugerah agama dan kenikmatan sains teknologi. Agama dan Ilmu pengetahuan-teknologi merupakan dua sisi yang tidak dapat dipisahkan satu sama lain. Ilmu adalah sumber teknologi yang mampu memberikan kemungkinan munculnya berbagai penemuan rekayasa dan ideide.

Adapun teknologi adalah terapan atau aplikasi dari ilmu yang dapat ditunjukkan dalam hasil nyata yang lebih canggih dan dapat mendorong manusia untuk berkembang lebih maju lagi. Namun, terlepas dari semua itu, perkembangan teknologi tidak boleh melepaskan diri dari nilainilai agama Islam. Sebagaimana adigum yang dibangun oleh Fisikawan besar, Albert Einstin yang menyatakan: "Agama tanpa ilmu akan pincang, sedangkan ilmu tanpa agama akan Buta”. Sebagai umat Islam kita harus menyadari bahwa dasar-dasar filosofis untuk mengembangkan ilmu dan teknologi itu bisa dikaji dan digali dalam Alquran sebab kitab suci ini banyak mengupas keterangan-keterangan mengenai ilmu pengetahuan dan teknologi.

Firman Allah SWT dalam surat Al-Anbiya ayat 80 yang artinya "Telah kami ajarkan kepada Daud membuat baju besi untuk kamu guna memelihara diri dalam peperanganmu."

Dari keterangan itu jelas sekali bahwa manusia dituntut untuk berbuat sesuatu dengan sarana teknologi. Sehingga tidak mengherankan jika abad ke-7 M telah banyak lahir pemikir Islam yang tangguh produktif dan inovatif dalam pengembangan ilmu pengetahuan dan teknologi. Kepeloporan dan keunggulan umat Islam dalam bidang ilmu pengetahuan sudah dimulai pada abad itu. Tetapi sangat disayangkan bahwa kemajuankemajuan itu tidak sempat ditindaklanjuti dengan sebaik-baiknya sehingga tanpa sadar umat Islam akhirnya melepaskan kepeloporannya. Lalu bangsa Barat dengan mudah mengambil dan menransfer ilmu dan teknologi yang dimiliki dunia Islam dan dengan mudah pula mereka membuat licik yaitu membelenggu para pemikir Islam sehinggu sampai saat ini bangsa Baratlah yang menjadi pelopor dan pengendali ilmu pengetahuan dan teknologi.

\section{Pembahasan}

\section{Sejarah Penerapan Teknologi Dalam Peradaban Islam}

Era keemasan Islam, para cendekiawan Muslim telah mengelompokkan ilmu-ilmu yang bersifat teknologis sebagai berikut; ilmu jenisjenis bangunan, ilmu optik, ilmu pembakaran cermin, ilmu tentang pusat gravitasi, ilmu pengukuran dan pemetaan, ilmu tentang sungai dan kanal, ilmu jembatan, ilmu tentang mesin kerek, ilmu tentang mesin-mesin militer serta ilmu pencarian sumber air tersembunyi. Para penguasa dan masyarakat di zaman kekhalifahan Islam menempatkan para rekayasawan (engineer) dalam posisi yang tinggi dan terhormat. Mereka diberi gelar muhandis. Banyak di antara ilmuwan Muslim, pada masa itu, yang juga merangkap sebagai rekayasawan.

Al-Kindi, misalnya, selain dikenal sebagai fisikawan dan ahli metalurgi adalah seorang rekayasawan. Selain itu, al-Razi juga yang populer sebagai seorang ahli kimia juga berperan sebagai rekayasawan. Al-Biruni yang masyhur sebagai seorang astronom dan fisikawan juga seorang rekayasawan.

Selain itu, peradaban Islam juga telah mengenal ilmu navigasi, ilmu tentang jam, ilmu tentang timbangan dan pengkuran serta ilmu tentang alat-alat genial. Menurut al-Hassan, teknik mesin dan teknik sipil yang digolongkan sebagai ilmu matematika, bukan satu-satunya subyek teknologis yang dikelompokkan sebagai sains. Para ilmuwan Muslim memberi perhatian pada semua jenis pengetahuan praktis, mengklasifikasi 
ilmu-ilmu terapan dan subyek-subyek teknologis berdampingan dengan telaah-telaah teoritis," ungkap Ahmad Y al-Hassan dan Donald R Hill dalam Islamic Technology: An Illustrated History. Sejumlah kitab dan risalah yang ditulis para ilmuwan Muslim tercatat telah mengklasifikasi ilmu-ilmu terapan dan teknologis. Menurut al-Hassan, hal itu dapat dilihat dalam sederet buku atau kitab karya cendikiawan Muslim, seperti; Mafatih al-Ulum, karya alKhuwarizmi; Ihsa al-Ulum (Penghitungan Ilmuilmu) karya al-Farabi, Kitab al-Najat, (Buku Penyelamatan) karya Ibnu Sina dan buku-buku lainnya.

Para rekayasawan Muslim telah berhasil membangun sederet karya besar dalam bidang teknik sipil berupa; bendungan, jembatan, penerangan jalan umum, irigasi, hingga gedung pencakar langit. Sejarah membuktikan, di era keemasannya, peradaban Islam telah mampu membangun bendungan jembatan (bridge dam). Bendung jembatan itu digunakan untuk menggerakkan roda air yang bekerja dengan mekanisme peningkatan air. Bendungan jembatan pertama dibangun di Dezful, Iran.

Selain itu, di era kekhalifahan para insinyur Muslim juga sudah mampu membangun bendungan pengatur air diversion dam. Bendungan ini digunakan untuk mengatur atau mengalihkan arus air. Bendungan pengatur air itu pertama kali dibangun insinyur Muslim di Sungai Uzaym yang terletak di Jabal Hamrin, Irak. Setelah itu, bendungan semacam itu pun banyak dibangun di kota dan negeri lain di dunia Islam. Pencapaian lainnya yang berhasil ditorehkan insinyur Islam dalam bidang teknik sipil adalah pembangunan penerangan jalan umum. Lampu penerangan jalan umum pertama kali dibangun oleh kekhalifahan Islam, khususnya di Cordoba. Pada masa kejayaannya, pada malam hari jalanjalan yang mulus di kota peradaban Muslim yang berada di benua Eropa itu bertaburkan cahaya. Selain dikenal bertabur cahaya di waktu malam, kota-kota peradaban Islam pun dikenal sangat bersih. Ternyata, pada masa itu para insinyur Muslim sudah mampu menciptakan sarana pengumpul sampah, berupa kontainer. Sesuatu yang belum pernah ada dalam peradaban manusia sebelumnya.

\section{Perspektif Islam Terhadap Teknologi}

Peradaban Islam sangat berbeda dengan Yunani, Romawi dan Byzantium dalam memandang teknologi. Para cendekiawan Muslim di era kekhalifahan menganggap teknologi sebagai sebuah cabang ilmu pengetahuan yang sah. Fakta itu terungkap berdasarkan pengamatan para sejarawan sains Barat di era modern terhadap sejarah sains di Abad Pertengahan.

Demikian pula ajaran Islam ia tidak akan bertentangan dengan teori-teori pemikiran modern yang teratur dan lurus dan analisa-analisa yang teliti dan obyekitf. Dalam pandangan Islam menurut hukum asalnya segala sesuatu itu adalah mubah termasuk segala apa yang disajikan oleh berbagai peradaban baik yang lama ataupun yang baru. Semua itu sebagaimana diajarkan oleh Islam tidak ada yang hukumnya haram kecuali jika terdapat nash atau dalil yang tegas dan pasti mengherankannya. Bukanlah Alquran sendiri telah menegaskan bahwa agama Islam bukanlah agma yang sempit? Allah SWT telah berfirman yang artinya "Di sekali-kali tidak menjadikan kamu dalam agama suatu kesempitan." .

Teknologi modern yang begitu pesat telah memasyarakatkan produk-produk teknologi canggih seperti Radio, televisi, internet, alat-alat komunikasi dan barang-barang mewah lainnya serta menawarkan aneka jenis hiburan bagi tiap orang tua, kaum muda, atau anak-anak. Namun tentunya alat-alat itu tidak bertanggung jawab atas apa yang diakibatkannya. Justru di atas pundak manusianyalah terletak semua tanggung jawab itu. Sebab adanya pelbagai media informasi dan alatalat canggih yang dimiliki dunia saat ini dapat berbuat apa saja kiranya faktor manusianyalah yang menentukan operasionalnya. Adakalanya menjadi manfaat yaitu manakala manusia menggunakan dengan baik dan tepat. Tetapi dapat pula mendatangkan dosa dan malapetaka manakala manusia menggunakannya untuk mengumbar hawa nafsu dan kesenangan semata.

Kemajuan teknologi dalam dunia kedokteran juga patut untuk kita apresisai secara kritis; proses cloning (bayi tabung) misalnya, telah mendapat tanggapan beragam dari para ulama; Sebagian kelompok agamawan menolak fertilisasi in vitro pada manusia karena mereka meyakini bahwa kegiatan tersebut sama artinya mempermainkan Tuhan yang merupakan Sang Pencipta. Juga banyak kalangan menganggap bahwa pengklonan 


$$
\begin{array}{r|c}
\text { Jurnal Sains Komputer dan Teknologi Informasi } & \text { Page } \\
\text { e-issn: 2655-7460. Volume i lssue, } 1 \text { November 2018 } & 5-10
\end{array}
$$

manusia secara utuh tidak bisa dilakukan sebab ini dapat dianggap sebagai “intervensi” karya Ilahi.

Sebaliknya, Sheikh Mohammad Hussein Fadlallah, seorang pemandu spiritual muslim fundamentalis dari Lebanon berpendapat, adalah salah jika menganggap kloning adalah suatu intervensi karya Ilahi.Peneliti dianggapnya tidak menciptakan sesuatu yang baru.Mereka hanya menemukan suatu hukum yang baru bagi ormanisme, sama seperti ketika mereka menemukan fertilisasi in vitro dan transplantasi organ. Professor Abdulaziz Sachedina dari Universitas Virginia mengemukakan bahwa Allah adalah kreator terbaik.Manusia dapat saja melakukan intervensi dalam pekerjaan alami, termasuk pada awal perkembangan embrio untukmeningkatkan kesehatan atau embrio splitting untuk meningkatkan peluang terjadinya kehamilan, namun perlu diingat, Allahlah Sang pemberi hidup

Islam sebagai agama paripurna yang mampu memberikan petunjuk bagi manusia. Ini semua tidak lepas dari karakter agama Islam sebagai rahmatan lil alamin. Memang dalam abad teknologi dan era globalisasi ini umat Islam hendaklah melakukan langkah-langkah strategis dengan meningkatkan pembinaan sumber daya manusia guna mewujudkan kualitas iman dan takwa serta tidak ketinggalan di bidang ilmu pengetahuan dan teknologi.

Peradaban modern adalah hasil kemajuan ilmu pengetahuan dan teknologi yang gemilang yang telah dicapai oleh manusia setelah diadakan penelitian yang tekun dan eksperimen yang mahal yang telah dilakukan selama berabad-abad. Maka sudah sepantasnya kalau kemudian manusia menggunakan penemuan-penemuannya itu guna meningkatkan taraf hidupnya. Kemajuan teknologi secara umum telah banyak dinikmati oleh masyarakat luas dgn cara yang belum pernah dirasakan bahkan oleh para raja dahulu kala.

Namun seiring dengan upaya meningkatkan ilmu pengetahuan dan teknologi kita pun harus jeli menentukan pilihan ini. Untuk apakah semua kemajuan itu? Apakah sekadar untuk menuruti keinginan-keinginan syahwat lalu tenggelam dalam kemewahan dunia hingga melupakan akhirat dan menjadi pengikut-pengikut setan? Ataukah sebaliknya semua ilmu dan kemajuan itu dicari untuk menegakkan syariat Allah guna memakmurkan bumi dan menegakkan keadilan seperti yang dikehendaki Allah serta untuk meluruskan kehidupan dengan berlandaskan pada kaidah moral Islam? Ada banyak tantangan yang harus kita jawab dengan pemikiran yang berwawasan jauh ke depan. Namun terlepas dari problema dan kekhawatiran-kekhawatiran sebagaimana diuraikan di atas kita sebagai umat Islam harus selalu optimis dan tetap bersyukur kepada Allah SWT.

Karena sungguhpun perubahan sosial dan tata nilai kehidupan yang dibawa oleh arus westernisasi dan sekularisasi terus-menerus menimpa dan menyerang masyarakat Islam tetapi kesadaran umat Islam untuk membendung dampak-dampak negatif dari budaya Barat itu ternyata masih cukup tinggi meskipun hanya segolongan kecil umat yaitu mereka yang tetap teguh untuk menegakkan nilai-nilai Islam.

Ilmu Pengetahuan dan Teknologi (IPTEK) menurut pandangan Al-Qur'an mengundang kita untuk menengok sekian banyak ayat Al-Qur'an yang berbicara tentang alam raya. Menurut ulama terdapat 750 ayat Al-Qur'an yang menjelaskan tentang alam beserta fenomenanya dan memerintahkan manusia untuk mengetahui dan memanfaatkannya. Allah SWT berfirman dalam QS Al-Baqarah ayat 31 yang artinya :"Dan dia ajarkan kepada Adam nama-nama (benda) semuanya, kemudian diperintahkan kepada malaikat-malaikat, seraya berfirman "Sebutkan kepadaku nama semua (benda) ini, jika kamu yang benar". Dari ayat di atas yang dimaksud nama-nama adalah sifat, ciri, dan hukum sesuatu. Ini berarti manusia berpotensi mengetahui rahasia alam semesta. Adanya potensi tersebut, dan tersedianya lahan yang diciptakan Allah, serta ketidakmampuan alam untuk membangkang pada perintah dan hukum-hukum Tuhan, menjadikan ilmuwan dapat memperoleh kepastian mengenai hukum-hukum alam. Karenanya, semua itu menghantarkan pada manusia berpotensi untuk memanfaatkan alam itu merupakan buah dari ilmu pengetahuan dan teknologi. Al-Qur'an memerintahkan manusia untuk terus berupaya meningkatkan kemampuan ilmiahnya. Jangankan manusia biasa, Rasul Allah Muhammad SAW pun diperintahkan agar berusaha dan berdoa agar selalu ditambah pengetahuannya (QS Yusuf : 72). 


\section{Kesimpulan}

Kebangkitan ilmu pegetahuan dan teknologi di kalangan umat Islam setidaknya memiliki beberapa syarat yang harus dipenuhi oleh kalangan Islam apabila berkehendak untuk membangkitkan kembali IPTEK di dunia Islam.

Pertama, kita menyadari dan memahami kembali bahwa tugas kita sebagai khalifah tidak lain adalah untuk memakmurkan bumi dan berupaya menciptakan bayang-bayang syurga di bumi. Alat untuk mengemban tugas tersebut adalah IPTEK.

Kedua, kalangan Islam harus menyadari dan memahami bahwa hampir seperdelapan ayat-ayat Al-Qur'an sebenarnya kita ditegur, agar kalangan Islam senantiasa mempelajari alam semesta, untuk berfikir dengan menggunakan penalaran yang sebaik-baiknya, untuk menjadikan kegiatan ilmiah sebagai bagian yang tidak terpisahkan dari kehidupan umat Islam.

Ketiga, kita harus ingat sabda Nab Muhammad SAW : " Sesungguhnya orang yang berilmu adalah pewaris Nabi", kalimat tersebut mempunyai dua sisi yang merupakan satu kesatuan. Sisi pertama, memang orang berilmulah yang berhak disebut sebagai pewaris Nabi, dan sisi kedua, orang-orang yang mewarisi akhlak Nabilah yang layak disebut sebagai pewaris Nabi. Dengan demikian orang memiliki ilmu dan berakhlakul karimah Nabi yang layak disebut pewaris Nabi dalam segala bidang ilmu apapun yang ditekuninya.

Keempat, Para penguasa (pengambil keputusan) hendaknya menyadari dan memahami bahwa kedudukan mereka sangat startegis dalam menumbuhkan suasan kehidupan ilmiah, karena tumbuh suburnya IPTEK ergantung pada kebijakan-kebijakan yang dilahirkan.

Kelima, para konglongmerat muslim dan seharusnya bersatu dalam suatu wadah untuk membiayai proyek atau program-program yang berkenaan dengan pengembangan IPTEK. Dan para pengasuh pondok pesantren mulai membuka diri pada IPTEK

Demikian syarat di atas, merupakan faktor penting bagi kebangkitan IPTEK di kalangan umat Islam.

\section{Referensi}

\section{Buku}

Armayanto, Harda. "Relevansi Islamisasi Ilmu Pengetahuan Kontemporer." 2009.

Agus, Bustanuddin. Pengembangan Ilmu-Ilmu Sosial: Studi Banding Antara Pandangan

Ilmiah Dan Ajaran Islam. Gema Insani, 1999.

Al-Hassan, Ahmad Y., And Donald Routledge

Hill. "Islamic Technology; An Illustrated

History." 1986.

Nashir, Haedar. Agama \& Krisis Kemanusiaan

Modern. Pustaka Pelajar, 1997.

Nugroho, Sigit Sapto. "Islamisasi Ilmu Pengetahuan; Basis Epistimologi Sains Modern." 2016.

Majid, Nurcholish. Islam: Doktrin Dan Peradaban. Yayasan Wakaf Paramadina, 1992.

Yuyansi, Yuyansi. Ilmu Pengetahuan Dan Teknologi Dalam Perspektif Al Qur'an. Diss. Uin Sunan Ampel Surabaya, 1999.

\section{Jurnal}

Anwar, Saepul. "Hakekat Manusia (Manusia Dimata Filosuf Dan Al-Qur'an Serta Kajian Tentang Inti Manusia)." Jurnal Kajian Pendidikan Agama-Ta'lim Vol 4.2-2006: 133.

Bakti, Andi Faisal, And Venny Eka Meidasari. "Trendsetter Komunikasi Di Era Digital: Tantangan Dan Peluang Pendidikan Komunikasi Dan Penyiaran Islam." Jurnal Komunikasi Islam 4.1 (2014).

Khobir, Abdul. "Hakikat Manusia Dan Implikasinya Dalam Proses Pendidikan." Forum Tarbiyah. Vol. 8. No. 1. 2010. 


\begin{tabular}{r|c} 
Jurnal Sains Komputer dan Teknologi Informasi & Page \\
e-issn: 2655-7460. Volume i Issue, i November 2018 & $5-10$ \\
\hline
\end{tabular}

Stapa, Zakaria, Ahmad Munawar Ismail, And Noranizah Yusuf. "Faktor Persekitaran Sosial Dan Hubungannya Dengan Pembentukan Jati Diri (Social Environmental Factors And Their Relation To Identity Formation)." Jurnal Hadhari: An International Journal (2012): 155-172.

Sachedina, Abdulaziz. The Islamic Roots of Democratic Pluralism. Oxford University Press, 2001.

Hilmy, Masdar. "Induktivisme Sebagai Basis Pengembangan Ilmu Pengetahuan Dalam Islam." Ulumuna 17.1 (2013): 97-126.
Nasution, Aulia Rosa. "Terrorism And Radicalism In The 21st Century As A Crime Against Humanity In The Perspective Of Law And Human Rights."

Ritonga, Mahyudin. "Pengaruh Klasifikasi Ilmu Terhadap Kurikulum Pai Dalam Perspektif Ulama." Edukasi: Jurnal Pendidikan Islam 5.2 (2017): 001-024.

Yanti, Maria Evvy, And S. T. T. Cipanas. "Sumbangsih Karya Nabi Perjanjian

Lama Bagi Guru Pendidikan Agama Kristen." Jurnal Pendidikan Penabur: 67. 